\title{
Modernização e concentração do transporte urbano em Salvador (1849-1930)1
}

\author{
Tramway modernization and concentration \\ in Salvador, Bahia, Brazil (1849-1930)
}

Alexandre Macchione Saes*

ReSUMO

O artigo recupera a história da formação das empresas de transporte urbano da cidade de Salvador entre os anos de 1849 e 1930. A proclamação da República marcou a fase inicial de modernização das empresas de transporte, em que a fusão de companhias e a incorporação de capitais estrangeiros possibilitaram a introdução dos bondes elétricos na capital baiana. Foi nesse contexto que dois grupos rivais iniciaram mais uma batalha no Brasil, agora pelos mercados de Salvador: de um lado, o grupo nacional da Companhia Brasileira de Energia Elétrica, e de outro lado, o grupo estrangeiro Light, liderado em Salvador pelo empresário norte-americano Percival Farquhar. Diante desse cenário de concorrência, o artigo analisa a relação entre as empresas e a Câmara Municipal de Salvador, instituição responsável por distribuir as concessões de transporte na cidade.

Palavras-chave: The Bahia Tramway, Light and Power Co.; Companhia Brasileira de Energia Elétrica e Salvador.

\begin{abstract}
This paper draws on the history of the formation of Salvador's city tramways between 1849 and 1930. The Proclamation of the Republic in Brazil (1889) started the modernization of the tramway companies which, through the merger of enterprises and the arrival of foreign capital, was responsible for the introduction of the electric tramways in Bahia's capital. Two rival groups, in this context, competed in the Brazilian market, now in Salvador: on the one hand, the national enterprise Companhia Brasileira de Energia Elétrica, and on the other, the foreign company Light, led by the North-American entrepreneur Percival Farquhar. In this context of competition, the paper analyses the relation between the enterprises and Salvador's Town Council, the institution responsible for tramway concessions in the city.

Keywords: The Bahia Tramway, Light and Power Co.; Companhia Brasileira de Energia Elétrica e Salvador.
\end{abstract}

\footnotetext{
* Doutorando em História Econômica - Unicamp. Rua Ministro Godoy, 679 apto. 73, Perdizes. 05015000 São Paulo - SP - Brasil. xixosaes@hotmail.com.
} 
A construção de um vasto sistema de infra-estrutura na virada para o século XX, incluindo a instalação de ferrovias, a formação de empresas de serviços urbanos de transporte e iluminação e a criação de um sistema bancário e industrial, foi reflexo das transformações da estrutura econômica que dinamizava o processo para a construção de sociedades capitalistas. No caso brasileiro, tais transformações foram estudadas de maneira exaustiva nos estados do Rio de Janeiro e São Paulo, principais beneficiados pelo desenvolvimento da economia cafeeira, e alguns anos depois da proclamação da República, as duas maiores e mais ricas cidades do país. Conseqüentemente, foi nessas capitais, a cidade do Rio de Janeiro como centro político do Império e da República, e a cidade de São Paulo como epicentro da economia cafeeira, que o processo de industrialização se mostrou vigoroso, impulsionando mudanças nas relações de trabalho, criando uma nova vida no mundo urbano e enriquecendo as elites locais.

Salvador, por sua vez, na transição do século XIX para o XX era uma cidade de contrastes. Como terceira maior capital brasileira, com 232.396 habitantes em 1899, e antiga capital da colônia portuguesa, Salvador ainda concentrava uma elite enriquecida pelo comércio de importação e exportação, pelo extinto tráfico negreiro e pelas emergentes empresas urbanas e indústrias. É natural que tenha circulado em Salvador a segunda linha de bondes elétricos do Brasil, no ano de 1897, ficando atrás somente da capital da República. E ainda, foi em Salvador que se instalou o primeiro e revolucionário elevador público do mundo, em 1873: o Elevado Hidráulico da Conceição, hoje conhecido como Elevador Lacerda. ${ }^{2}$ Entretanto, tais aspectos modernos não condiziam com a outra Salvador, que sofria com a decadência e estagnação da economia regional, com o empobrecimento de grande parte da população local, e com o fato de ser capital do estado e ter de lutar diariamente contra surtos epidêmicos.

De qualquer maneira, foi nesse ambiente de contrastes, de uma elite poderosa regionalmente e de uma população extremamente pobre, e de uma arquitetura onde inovações como o Elevador Lacerda dividiam a paisagem com deteriorados cortiços, que uma empresa nacional, a Companhia Brasileira de Energia Elétrica (ainda como Guinle \& Co.), e uma estrangeira, The Bahia Tramway, Light and Power Co. (na liderança de Percival Farquhar), ${ }^{3}$ estenderam seus conflitos das cidades de São Paulo e Rio de Janeiro para Salvador. ${ }^{4}$ Estas eram as três maiores cidades brasileiras do período, além de centros com importância econômica regional e nacional. No caso específico de Salvador, mesmo não fazendo mais parte do centro dinâmico da economia nacional, a capital baiana mantinha um dos principais portos da região, exportando acima de tudo açúcar, fumo e cacau. 
Em meados do século XIX, "embora duplamente periférica, a Bahia foi capaz ... de criar uma rede de articulações e trânsito urbano e interurbano à sua própria imagem, para servir a seus desígnios" (Sampaio, 2005, p.159). Esse era o início do processo de modernização da cidade. Acompanhando as demandas do processo de urbanização, Salvador foi palco da formação de companhias locais de transporte que começavam a articular a cidade. Assim, a introdução de tais inovações na economia soteropolitana, mesmo ao beneficiar apenas uma parte restrita da população, acabava por transformar a vida de todos os seus habitantes.

Vale ressaltar que tanto durante o período imperial quanto durante a Primeira República as leis federais e estaduais sobre as concessões de transporte público e urbano legislavam apenas por questões genéricas, como a concessão de cachoeiras para a produção de energia elétrica, a isenção de impostos alfandegários e a duração máxima de noventa anos para as concessões. Contudo, abria-se determinante espaço para o poder municipal, sendo definidas entre a Prefeitura e a Câmara dos Vereadores as concessões sobre o serviço de transporte. Os vereadores definiam questões como a autorização para o funcionamento da concessionária, a duração dessa concessão até o limite de noventa anos e qual a região de atendimento dentro do município.

Na literatura, a economia baiana no período de Primeira República foi pouco retratada, e menos numerosos ainda são os trabalhos sobre o sistema de serviços urbanos em Salvador nesse período. Nossos objetivos neste artigo são, portanto: 1) Recuperar a história das empresas de transporte público e urbano na cidade de Salvador durante a Primeira República; e 2) Estudar os conflitos sobre as concessões do serviço de bondes entre a empresa estrangeira Bahia Light e a nacional Companhia Brasileira de Energia Elétrica durante as duas primeiras décadas do século XX. Para tanto, no intuito de compreender o desenrolar dos conflitos, considerando a importância do poder local atuante na Câmara Municipal (chamado de Conselho Municipal da cidade de Salvador), devemos atentar às articulações entre empresas/empresários e as elites de Salvador.

\section{A EMERGÊNCIA DAS EMPRESAS DE BONDE DE SALVADOR: A FASE IMPERIAL}

A história dos transportes públicos e urbanos de Salvador teve origem em meados do século XIX, quando o então presidente de Província, barão de Caçapava, publicou a Lei no 224, de 4 de maio de 1845, que dava direito de 
dez anos de concessão para aqueles que instalassem linhas de "omnibus" na cidade. Essa preocupação do presidente de Província estava em consonância com as inovações que surgiam na Europa e nos Estados Unidos, e que logo eram assimiladas na capital do Império, o Rio de Janeiro.

A instabilidade política dos anos seguintes à promulgação da lei espantou possíveis concessionários, e o governo sem sucesso tentou estimular sua própria companhia. Quatro anos depois, em 1849, o italiano Rafael Ariani arrendou a iniciativa do governo para promover o transporte urbano na cidade. Com apoio de seus filhos, Giusto e Luciano, Rafael constituiu uma empresa familiar que revolucionaria o transporte da cidade, ao implementar um transporte urbano e coletivo moderno e com regularidade. Os serviços oferecidos pelas "gôndolas" de Ariani eram de grande excelência, de maneira que as poucas empresas existentes na cidade durante a década de 1850 não resistiram à concorrência com os Ariani por muito tempo. Em 1859, os Ariani formaram a Companhia Posta Baiana, com apoio do influente deputado provincial Francisco Justiniano de Castro Rabelo e de mais 115 ilustres acionistas da elite soteropolitana.

Por maiores que fossem os esforços da empresa de Rafael Ariani, Salvador no início de 1860 ainda mantinha um sistema de transporte precário e pouco articulado, fundamentalmente em razão da própria irregularidade do terreno da cidade. Dividida entre Cidade Baixa, a região comercial de importação e exportação, Cidade Alta, a sede do poder político-administrativo e religioso, e os arrabaldes, onde se localizava a aristocracia soteropolitana, a população da cidade demandava cada vez mais o desenvolvimento do sistema de transportes para a articulação dessas diferentes regiões.

Na década de 1860 as condições tornaram-se mais favoráveis para a expansão dos serviços de transporte. De um lado, um importante fluxo de capital inglês possibilitou a implementação das primeiras ferrovias no país, inclusive na Bahia, enquanto empresários da região viam novas possibilidades de investimento em empresas públicas e urbanas, já que o tráfico de escravos havia cessado em 1850 e, teoricamente, um excedente de capital circulava pela sociedade. Com a intensa ligação entre empresários e os bancos da região, o capital investido nos meios de transporte público de Salvador, nessa fase pioneira, era de origem dos empresários locais: emerge então o caráter familiar das primeiras companhias que se constituíam.

Nesse novo contexto de metamorfose da riqueza da elite de Salvador é que foram criadas as primeiras empresas de bondes da cidade (numa primeira fase de articulação da cidade por tração animal): a Companhia Transpor- 
tes Urbanos (1864), a Companhia Trilhos Centrais e a Companhia de Veículos Econômicos (1869), e a Companhia Linha Circular da Bahia (1883). Até a década de 1890, essas empresas ainda mantinham serviços arcaicos, com bondes movidos a tração animal, mas que já eram suficientes para facilitar a ligação entre regiões. Para auxiliar na articulação vertical da cidade, entre cidade baixa e alta, foram inaugurados dois elevadores: o Elevador Hidráulico da Conceição em 1873 (atual elevador Lacerda) e o Elevador Hidráulico do Taboão em 1896; e três planos inclinados: Isabel e Gonçalves em 1889, e Pilar em 1897.5

Com a morte de Rafael Ariani, seus filhos Luciano e Giusto substituíram o serviço de "gôndolas" pelo de bondes por tração animal, com a formação da firma Ariani em 1864. Contudo, tal empreendimento não teve êxito, pois três anos depois foi incorporado por Monteiro \& Carneiro, empresa fundada pelos empresários Paulo Pereira Monteiro e Nicolau Carneiro Filho. A união entre as empresas criava a Companhia Veículos Econômicos, com mais de 250 sócios comanditários e servindo as regiões comerciais da cidade baixa de Salvador. Mas, em decorrência das inúmeras dificuldades a superar, como o marasmo burocrático e os conflitos por interesses, a linha de bondes da Companhia Veículos Econômicos só começou a funcionar em 28 de maio de 1869, três anos depois de a companhia ser organizada. Por mais que importantes membros da sociedade baiana estivessem entre os sócios da empresa, a Companhia Veículos Econômicos se envolveu, na década de 1870, em diversos conflitos com o governo, na cobrança das passagens, na isenção de impostos e na definição de áreas de concessão.

Perdendo a concessão dos serviços na cidade baixa, novamente os irmãos Ariani empreenderam esforços para formar uma nova empresa de transporte urbano, agora na cidade alta. Aliados outra vez com o deputado Francisco Justiniano de Castro Rabelo, que possuía importantes relações políticas com os grupos locais, os três empresários fundaram em 1869 a Companhia Trilhos Centrais, com 218 contos de réis, 120 destes recebidos da venda da concessão dos serviços da cidade baixa para Monteiro \& Carneiro. O percurso da nova empresa de bondes ligava o centro da cidade alta com o Matadouro, propriedade de Castro Rabelo. No final do Império, depois da morte dos irmãos Ariani, o deputado assumiu toda a empresa em leilão organizado em 7 de julho de 1887, por meio do lance de 340 contos de réis.

Para a articulação das cidades alta e baixa o engenheiro Antônio Lacerda foi pessoa determinante. Em 1864 o empresário fundava a Companhia de Transportes Urbanos, com o objetivo de atender parte da população dos bair- 
ros residenciais da cidade alta mediante bondes e realizar a ligação entre os dois níveis da cidade. Enquanto Antônio Lacerda gastava toda a fortuna acumulada por sua família na construção do elevador entre 1869 e 1873, a Companhia Transportes Urbanos inaugurou sua primeira linha de bondes em 1869, ligando o centro da cidade aos bairros nobres de Salvador. O inovador projeto do Elevador da Conceição (depois Elevador Lacerda em homenagem ao seu construtor) foi inaugurado em 1873, mas levou Antônio Lacerda à falência. Ele seria exonerado da empresa em 1875.

Finalmente, ainda nessa primeira fase do transporte urbano por tração animal, seria formada, no anoitecer do Império, a Companhia Linha Circular de Carris da Bahia. Sua fundação, comandada pelo engenheiro João Ramos de Queiroz, foi autorizada pela Lei Provincial no 2.046, de 20 de julho de 1883, por 500 contos de réis. A empresa inicialmente formada no Rio de Janeiro, e logo transferida para Salvador, tinha como objetivo concorrer com as empresas já estabelecidas, recebendo para tanto 50 anos de privilégio para uso e gozo de linha circular de carris urbanos. Pela primeira vez uma nova empresa buscava enfrentar os domínios das concessões de outras, que até então atuavam em zonas previamente delimitadas. Quanto ao trajeto das linhas de bondes, a Companhia Linha Circular passou a percorrer a populosa e comercial região da Sé, cortando os trilhos para a Baixa do Pelourinho e a parte interior da Península de Itapagipe. Na ligação vertical, João Ramos de Queiroz e Manuel Francisco Gonçalves construíram o Plano Inclinado Gonçalves, o Plano Inclinado Isabel (1889) e o Plano Inclinado do Pilar (1897).

A Proclamação da República gerou na Bahia intensas disputas pelo poder local. A crise política que duraria até a intervenção de Floriano Peixoto, poucos anos depois, impulsionou a crise econômica no estado da Bahia. Paralelamente, as companhias de bondes passavam a sofrer com os crescentes custos provenientes da manutenção dos animais utilizados na tração dos bondes. Como exemplo, em 1878, o dispêndio da Companhia Veículos Econômicos foi de 82 contos de réis com animais, enquanto os salários dos empregados não alcançavam 30 contos de réis. Esses altos custos eram referentes à importação e à alimentação dos burros, como também às constantes perdas de animais pelas repetidas epidemias. Porém, nos Estados Unidos o sistema de bondes elétricos estava em plena expansão. Anos depois seria introduzido no Rio de Janeiro, indicando que o antigo sistema de tração animal se esgotara.

Nesse cenário de precariedade financeira, a Companhia Transportes Urbanos não suportou a concorrência com a Companhia Linha Circular na cidade alta de Salvador e foi absorvida por sua concorrente em 1897. Em con- 
dições semelhantes, a Companhia Veículos Econômicos foi reorganizada pelo coronel Antônio Francisco Brandão, que em 1894 havia conquistado a parte da concessão da Linha Circular na cidade baixa, e com a fusão dessas concessões formava-se a Companhia Carris Elétricos em 1895, a primeira empresa com um projeto de eletrificação de suas linhas. Portanto, os anos seguintes à proclamação da República marcariam o final dessa primeira fase de fornecimento dos serviços de transporte urbano por meio da tração animal. As empresas precisavam modernizar-se e introduzir nova tecnologia que invariavelmente exigiria maior quantidade de capital: era o fim das empresas familiares, e o início da aliança entre grandes empresas e o capital internacional.

\section{A ELETRIFICAÇÃO DAS LINHAS DE BONDES: AS GRANDES EMPRESAS ENTRAM EM CENA}

O final do século XIX no Brasil foi marcado pela febre das elites locais, sobretudo nas capitais estaduais, para a modernização das cidades por meio da introdução de inovações no mundo dos serviços: era o período de Belle Époque, em que a energia elétrica transformava a vida urbana pela ampliação da iluminação pública e pela melhoria dos serviços de transporte urbano. E Salvador, mesmo não se beneficiando diretamente do desenvolvimento econômico das exportações de café e, por isso, ficando à margem da nova elite político-econômica brasileira ligada ao eixo São Paulo, Minas Gerais e Rio de Janeiro, manteve uma forte aristocracia que dividia o poder político nordestino com Pernambuco.

Em 4 de junho de 1898, o intendente de Salvador, Antônio Araújo, decretou a Lei $\mathrm{n}^{\circ} 330$, no sentido de estimular a substituição dos bondes de tração animal por carros elétricos. As empresas teriam três anos para realizar a substituição e a unificação de bitolas nos padrões determinados pelo Conselho Municipal, e desta maneira, renovariam a concessão por mais trinta anos. ${ }^{6}$ Contudo, a mudança de tecnologia requereria das companhias locais grandes somas de capital, para a instalação não só de linhas elétricas e de novos bondes, como também de usinas geradoras de energia. Tamanho capital e tecnologia dificilmente estariam disponíveis em tais empresas locais. Assim, o projeto de eletrificação das linhas de bonde começou a ser colocado em prática apenas em 1896, quando a empresa alemã Siemens \& Halske foi contratada para esse fim pela Companhia Carris Elétricos (sucessora da Companhia Veículos Econômicos). Além de deter a tecnologia para a eletrificação, a empresa 
alemã tinha o capital necessário para tal investimento. Assim, em 14 de março de 1897 a Siemens inaugurava em Salvador, na cidade baixa, a segunda linha de bondes elétricos do Brasil.

Na cidade alta, entretanto, desrespeitando a Lei nํㅜ 330, a Companhia Linha Circular (CLC), que havia absorvido a Transportes Urbanos e se associado à Trilhos Centrais, mesmo eliminando a concorrência nessa área da cidade, em 1905 ainda não havia elaborado seu projeto de eletrificação. A monopolização dos serviços na cidade alta pela Companhia Circular tivera início entre os anos de 1882 e 1887, quando o mormo, doença de fácil transmissão e letal aos animais, dizimou grande parte do plantel das empresas urbanas de Salvador. Tanto a Veículos Econômicos como a Transportes Urbanos foram seriamente atingidas e entraram em profunda dificuldade financeira. A Companhia Veículos Econômicos acabou por se reestruturar, enquanto as dificuldades da Companhia Transportes Urbanos aumentavam com a crise econômica gerada também pela abolição da escravatura e mudança de regime, tornando-se insustentáveis com as epidemias que quase dizimaram todos os animais da empresa.

Assim, em 1896, restou à empresa desfazer-se de parte de seus bens, como o custoso elevador do Taboão, logo após sua inauguração. Tal ação não foi suficiente, e no ano seguinte a Companhia Linha Circular comprou todos os bens da empresa (além do elevador Taboão, o elevador Lacerda e as linhas de bonde) e assumiu as concessões da Companhia Transportes Urbanos por 940 contos de réis. $^{7}$

Já no que diz respeito à Companhia Trilhos Centrais, fundada em 1869 para ligar o centro da cidade ao matadouro, uma relação de entendimento estreitou o desenvolvimento dessa empresa com a Companhia Linha Circular. A preocupação primordial da Companhia Trilhos Centrais era estabelecer o transporte de mercadorias em direção à região sudoeste da cidade alta de Salvador. A Companhia Linha Circular, com a aquisição da Companhia Transportes Urbanos passava a controlar as regiões mais movimentadas da cidade alta, além da ligação com os arrabaldes, onde viviam as classes altas. A associação com a Companhia Trilhos Centrais previa que a Linha Circular poderia passar a realizar o fornecimento de energia elétrica para a modernização das linhas de bondes das duas empresas. Esse processo de eletrificação das linhas só seria possível com a chegada do financeiramente poderoso grupo de Cândido Gaffrée e Eduardo Guinle. Em 1905 a empresa carioca Guinle \& Co. passava a atuar no mercado soteropolitano assumindo por meio da compra 
de ações a companhia Linha Circular, com o objetivo de substituir a tração animal pela elétrica.

A empresa carioca havia sido formada pelos empresários Eduardo Guinle e Candido Gaffrée. Já no final do século XIX, esses empresários controlavam a empresa Gaffrée \& Guinle, voltada para serviços de construção de ferrovias, a concessão do Porto de Santos e a representação de equipamentos elétricos no Brasil. Dessa empresa, em 1903, Eduardo Guinle Filho comandou a fundação da Aschoff \& Guinle, que pouco tempo depois se tornava a Guinle \& Co., cuja preocupação era atender serviços de transporte e iluminação nas cidades brasileiras. Esse grupo além de iniciar grandes conflitos para assegurar as concessões das cidades de São Paulo e Rio de Janeiro, conseguiu atender outras importantes cidades brasileiras como Niterói, São Gonçalo e Petrópolis, no Rio de Janeiro. Em 1909, todas as propriedades de Guinle \& Co. passaram para a Companhia Brasileira de Energia Elétrica, empresa também formada por Eduardo Guinle, que controlou os serviços de transporte e iluminação de diversas cidades no Brasil.

Em Salvador, finalmente, em 25 de setembro de 1906, por meio da Lei $n^{\circ}$ 810, que reafirmava os preceitos da Lei no 330, com a aquisição da Companhia Linha Circular pela empresa Guinle \& Co. (empresa representante da produtora norte-americana de materiais elétricos, General Electric, que lhe dava suporte) e com investimentos de 780 contos de réis, a cidade alta pôde começar a comemorar a eletrificação de suas linhas. ${ }^{8}$ Ainda em 25 de setembro de 1906, a Lei no 817 determinava a unificação dos direitos para a Siemens \& Halske com aqueles existentes para a Companhia Linha Circular. Ou seja, além de poder servir à iluminação das vias atendidas, a empresa teria também a isenção de impostos alfandegários para a construção de novas linhas de transporte. ${ }^{9}$ A família Guinle, que já no início do século XX era a representante dos produtos da empresa General Electric na cidade do Rio de Janeiro, aproveitou-se dessa relação com a norte-americana G.E. para empregar a mais moderna tecnologia estrangeira nas concessões brasileiras.

$\mathrm{Na}$ cidade baixa, a empresa alemã acabou usufruindo pouco de seus direitos, afinal, em 5 de novembro de 1907 era assinado o termo de transferência dos negócios da Siemens \& Halske, por seu diretor Emil Hayn, para a The Bahia Tramway, Light \& Power Company, diante do representante da empresa norte-americana, Odilon Octaviano dos Santos. ${ }^{10}$ Essa transação seguia um acordo previamente realizado na Cidade do México (1903) e no Rio de Janeiro (1904) entre a Siemens e a Light, em que a Siemens passava as concessões de serviço para a empresa norte-americana, enquanto esta última se compro- 
metia a utilizar todos os equipamentos da empresa alemã e manter parte dos seus antigos diretores na nova diretoria da Light (Armstrong \& Nelles, 1988, p.89). Assim, Emil Hayn assumiria o cargo de diretor geral da Bahia Light nos primeiros anos de serviço.

Em 1905, Percival Farquhar organizou a The Bahia Tramway, Light \& Power Co., em Portland, Maine, por 3,5 milhões de dólares de capital social e mais 3,5 milhões de dólares em bônus. ${ }^{11}$ Para tanto, a empresa se aproveitou da estrutura administrativa e financeira da Light do Rio de Janeiro, fundada em parceria com Frederick Pearson e Alexander Mackenzie. Já em 3 de abril do ano seguinte, Farquhar teria autorização do presidente Rodrigues Alves, pelo decreto $\mathrm{n}^{\circ}$ 5.957, para funcionar em Salvador. Farquhar, em 1906, também já havia adquirido a Compagnie d'Eclairage de Bahia, deixando esta como subsidiária responsável pelos serviços de iluminação enquanto a Bahia Light cuidaria dos serviços de transporte. Em pouco tempo a empresa já demonstraria grande rentabilidade, remetendo lucros para o exterior, em 1907, de 56 mil libras pelos serviços de transporte e mais 17 mil libras recebidas da d'Eclairage. Contudo, o desejo de Percival Farquhar era manter todos os privilégios possíveis dentro dos contratos de concessão estabelecidos entre empresas e municipalidade, gerando constantes conflitos entre as companhias concessionárias para adquirir melhores garantias e áreas de concessão.

Em comparação com as duas principais cidades do país, São Paulo e Rio de Janeiro, Salvador também estava passando por um momento de concentração das empresas prestadoras de serviços. Contudo, diferentemente das duas outras capitais, em que já no final da primeira década do século XX a empresa canadense Light conseguiu monopolizar o fornecimento de energia e a prestação do serviço de transporte urbano, a divisão geográfica de Salvador entre cidade alta e cidade baixa criou dois mercados distintos. Enquanto na cidade baixa os carros da Bahia Light cortavam as regiões portuárias e comerciais, na cidade alta eram os carros da Companhia Linha Circular e da Companhia Trilhos Centrais, sob a direção de Guilherme Guinle, que controlavam o tráfego entre o centro e os arrabaldes. Essa peculiaridade da capital baiana gerou uma preocupação especial do Conselho Municipal (a Câmara Municipal de Salvador) em criar uma regulamentação que abarcasse todas as concessões, com a intenção de superar a relação direta entre empresas e municipalidade.

Assim, a antiga lei de regulamentação do transporte de bondes promulgada por Francisco de Paula em 28 de dezembro de 1889, que regulava o serviço dos cocheiros, dos carros, carroças e animais, dos horários e tarifas, foi 
complementada por uma nova lei sobre os serviços de tramways, isso é, os bondes elétricos. Apresentada em 27 de fevereiro de 1907, a regulamentação se estendia em termos gerais sobre as concessões e a operação do serviço. A partir de 1907, todos os novos ramais deveriam ser autorizados pelo Conselho Municipal, mantendo distância de 500 metros de outras concessões, obedecendo aos limites tarifários estipulados pela tabela de preços, de no máximo 100 réis por zona de atendimento, e oferecendo a tabela de horários pretendidos para saídas e chegadas. Essa lei reafirmou os trajetos originais das empresas concessionárias e estendeu isenção tarifária para todas as empresas que colocassem em prática os projetos de eletrificação de suas linhas. Os motorneiros deveriam ser cadastrados e respeitar o limite de velocidade de $15 \mathrm{~km} / \mathrm{h}$ "e muito menos do que isso para ladeiras". Finalmente, todas as linhas seriam fiscalizadas pela Intendência, com fiscais recrutados pelo Conselho Municipal, mas pagos pelas empresas concessionárias. ${ }^{12}$

A rigorosa fiscalização da municipalidade de Salvador foi uma inovação nas leis impostas pelas prefeituras no Brasil. Diante da falta de regulamentação federal sobre os serviços de bondes e iluminação elétrica, já que a legislação federal e estadual apenas se posicionava sobre a utilização dos recursos hidráulicos, ${ }^{13}$ ficava a cargo das Câmaras Municipais a decisão quanto às empresas e à maneira pela qual seria fornecido o serviço público. Os fiscais tinham como função cobrar das empresas assiduidade nos horários de saída e chegada dos carros, de realização das obras de ampliação das linhas, e de reforma das vias por onde os veículos passavam.

As multas eram constantes, e principalmente a empresa Bahia Light colecionava infrações por falhas na condução dos serviços. Em relatório da companhia estrangeira para a Intendência Municipal, o diretor geral Emil Hayn questiona as seguintes multas:

Diz a Bahia Tramway Light and Power Company que havendo recebido do Ilm. Sr. Engenheiro Fiscal ofícios datados de 14 e 17 do corrente, comunicandolhe haver sido multada no dia 12 , por infração do regulamento relativo às empresas de carris urbanos (L. n.880), e em 14 pela do art. 13 do mesmo regulamento, sendo que naquela data por não cumprir o horário provisório e nesta que permanecera no serviço diário carros sem a taboleta indicativa do destino dos mesmos; e outrossim, em 17 por haver o carro n.48 passado na Agulha do Papagaio sem a devida precaução, resultando em descarrilamento o que caracteriza a infração dos art. 25 e $75 .{ }^{14}$ 
Hayn exigia a suspensão das multas por parte da Intendência, alegando excesso de rigor contra a empresa. Dois anos depois da promulgação da lei municipal sobre a regulamentação dos transportes urbanos, a Bahia Light já somava cerca de 15 contos de réis em multas com o município por problemas na prestação do serviço.

Para piorar a situação da Bahia Light, em 5 de outubro de 1909 um bonde da empresa atropelou e matou um cego, provocando revolta entre a população. O engenheiro Willian Mitchell, um dos diretores responsáveis pela Light em Salvador e braço direito de Farquhar no Brasil, dirigiu-se ao local no intuito de acalmar a situação, mas sua presença gerou ainda maior revolta: as versões são inúmeras, desde que ao chegar de bonde, Mitchell passou por cima do cadáver; ou que na tentativa de acalmar os ânimos disse que "vida de brasileiro se paga com cem mil-réis"; ou finalmente, que já ao chegar ao local do acidente foi recebido a pedradas pela população (Barros, 1982, p.33). De qualquer maneira, o resultado foi uma marcha popular contra os bens da Light, com a destruição de bondes e aparelhos de iluminação. Dias depois, a Light anunciava prejuízos em torno de 13 contos de réis, ${ }^{15}$ enquanto novamente Emil Hayn exigia que a prefeitura tomasse atitudes em resposta ao evento: "Diante dos tristes acontecimentos de hoje e da quase absoluta falta de garantias para o pessoal e material desta Companhia, comunico a V. Ex. que a Companhia não poderá restabelecer o tráfego dos bondes enquanto não se tornem efetivas as garantias que solicito a V. Ex... ${ }^{16}$

Nesse mesmo período de instalação da Bahia Light, e já dos primeiros conflitos da empresa com a municipalidade, a empresa de Guinle \& Co., que havia adquirido a Companhia Linha Circular, passou a implantar o sistema de bondes elétricos. A energia elétrica era produzida pelas pequenas usinas termelétricas da Canela (uma usina provisória que funcionou somente entre 1906 e 1907) e da Preguiça, de 4 mil kW, mas o suficiente para a Companhia Linha Circular fornecer energia aos bondes e transmitir o excedente para terceiros. Contudo, no projeto de Guilherme Guinle, diretor da empresa em Salvador, era imprescindível iniciar a construção de usinas hidroelétricas para baratear e ampliar a produção de energia elétrica. E aproveitava-se, para tanto, do bom trânsito que o empresário gozava nos grupos influentes da sociedade soteropolitana, ${ }^{17}$ inverso da relação conflituosa entre Bahia Light e poderes locais. Com isso, já em 1907 se iniciaram as obras para a construção da usina de Guinle \& Co. no rio Paraguaçu - no salto de Bananeiras, município de São Felix -, aprovados pelo Decreto Estadual nº 389, de 27 de março de 1906, com base no Art. 7, sobre a exploração industrial da energia elétrica, da 
Lei Federal no 634, de 28 de dezembro de 1905. Pouco depois, ampliava-se o contrato para os saltos de Marcela e Gameleira, no município de Cachoeira. ${ }^{18}$

A divisão geográfica da cidade de Salvador assegurou tênue paz entre a Light e a Guinle \& Co., restritas respectivamente aos mercados das cidades baixa e alta. Só em 1909 os conflitos entre as duas empresas pareceram se acirrar na capital baiana. Em parte, a crise era reflexo do crescente conflito entre as duas empresas nos mercados de São Paulo e do Rio de Janeiro, mas também respondia à ampliação dos serviços da Guinle \& Co. (que naquele ano passou a ser Companhia Brasileira de Energia Elétrica). Esta buscava fornecer iluminação elétrica para a cidade, em concorrência com os serviços de iluminação a gás distribuído pela subsidiária da Bahia Light, Compagnie d'Eclairage, e ainda lançava suas linhas de bondes para a cidade baixa.

No que diz respeito às concessões do serviço de transporte, em 2 de setembro de 1911 a Companhia Trilhos Centrais entrou com recurso para que se negasse o pedido de concessão do empresário Durval Sá Pereira, que pretendia ligar a cidade alta à cidade baixa por meio de bondes elétricos, através de um túnel partindo do Taboão rumo à Praça dos Veteranos. A justificativa da Companhia Trilhos Centrais era que Sá Pereira estaria invadindo parte da zona, na cidade alta, de concessão da empresa. ${ }^{19}$ Contudo, menos de um ano depois de barrar o projeto de Durval Sá Pereira, a empresa Trilhos Centrais encampou o projeto do empresário e levou ao Conselho Municipal o estudo da ligação entre as cidades alta e baixa pelo túnel.

Desta vez, era a Companhia Trilhos Centrais que invadia a área de concessão de outra empresa: da Bahia Light, na cidade baixa. Logo, em 17 de julho de 1912, as comissões de Justiça e Fazenda debatiam-se sobre o pedido da Companhia Trilhos Centrais e da reclamação da Bahia Light. Em reunião, afirmava-se:

Funda-se a reclamação ou protesto no fato de gozar o reclamante "Light and Power" de um privilégio de zona de 500 metros concedido pela lei n. 817 de 25 de setembro de 1906, zona que segundo a referida concessão será invadida". Já em defesa a Trilhos Centrais lembrava-se: "Se é um fato que o reclamante (Bahia Light) goza de um privilégio de zona de 500 metros para cada lado de sua linha, não é menos certo que a "Trilhos Centrais" também goza de um privilégio de zona de 500 metros para cada lado de sua linha, nos termos da lei n.816 de setembro de 1906, sendo ainda para notar que, como consta no livro de contratos existente na Intendência a "Trilhos Centrais" adquiriu em privilégio de 
zona antes da Reclamante, por isso que firmou o seu contrato em 10 de novembro de 1906, quando o reclamante só o fez em 24 de outubro de 1907, quase um ano depois. ${ }^{20}$

No ano seguinte, depois de recursos das duas empresas, o Conselho $\mathrm{Mu}$ nicipal votou a emenda sobre a construção do túnel ligando a cidade baixa à alta: mais de dois terços dos componentes do Conselho aprovavam e concediam à Companhia Trilhos Centrais o direito de construir a passagem pelo túnel ligando o Taboão à Praça do Deodoro. Farquhar logo percebeu que sua influência na cidade era pequena e cada vez mais questionada: as questões sobre o pagamento das multas imputadas à Bahia Light pelo município continuavam em andamento. Farquhar alegava que não pagaria tal valor referente às multas porque era aproximadamente o mesmo valor da destruição de seu patrimônio durante o incidente com o cego no centro de Salvador, em 1909.

Para piorar ainda mais o conflito entre a Bahia Light e os poderes municipais, os serviços de iluminação realizados pela subsidiária Compagnie d'Eclairage, além de custosos continuavam em péssimo funcionamento. Em 9 de março de 1911, a Companhia Brasileira de Energia Elétrica entrou com petição no Conselho Municipal para que autorizasse a venda de sua energia excedente para a Compagnie d'Eclairage, por 100 réis, para que esta pudesse repassar para o município por menores preços. Mas já era tarde, o Conselho Municipal estava decidido a encampar os bens da companhia de iluminação, considerando ser este um ato de soberania e de defesa do serviço de utilidade pública: pagando-se a indenização devida à empresa, a encampação seria um ato legal.

Longas discussões tomaram jornais e os debates do Conselho Municipal, ${ }^{21}$ tanto sobre a constitucionalidade da encampação aprovada pelos vereadores, quanto sobre o valor da indenização. Em 5 de julho de 1911, diante da Lei no 906, finalmente o Intendente Carneiro Rocha sancionou a lei de encampação não só da d'Eclairage, como também da Bahia Light. Em 1913, a Comissão de Justiça aprovava o valor da indenização de 20.238:095\$238 réis, e efetivamente as propriedades da Bahia Light passavam para as mãos da municipalidade. Entretanto, faltava o município arrecadar tal valor para efetuar o pagamento. ${ }^{22}$ Era a primeira grande derrota da Light no Brasil. No mesmo período da encampação em Salvador, entretanto, formava-se a Brazilian Traction Light and Power, unindo as duas empresas bem-sucedidas de São Paulo e do Rio de Janeiro.

A indenização a ser paga à Bahia Light levou longos anos para ser con- 
solidada, e Percival Farquhar continuaria alegando pelo resto da vida que o valor total a receber do município de Salvador não havia sido atingido. A concessão da empresa era assumida naquele momento pelo município, cujas condições financeiras para gerir tais serviços eram extremamente precárias. No entender de McDowall (1988, p.213):

A Bahia Tramway faliu porque negligenciou a construção de uma resistente aliança com grupos locais. Diferentemente das companhias do Rio de Janeiro e de São Paulo, a empresa baiana não foi dirigida por um homem do calibre de Alexander Mackenzie, para realizar alianças políticas e com a elite local, e assim, prevenindo o isolamento da empresa e o possível ostracismo.

\section{RUMO AO MONOPÓLIO: COMPANHIA LINHA Circular após a Primeira Guerra}

A expansão dos serviços no período da Primeira Guerra Mundial foi dificultada pelo encarecimento ou pelo simples desaparecimento das matériasprimas necessárias para a construção e manutenção das linhas de bondes e das usinas geradoras de eletricidade. Tanto a Companhia Linha Circular como a Companhia Trilhos Centrais haviam ampliado substancialmente suas linhas entre 1906, o ano da intervenção da empresa Guinle \& Co., e 1912, pouco antes do início do conflito mundial. Em 1921, nos relatórios das empresas para o Conselho Municipal, os diretores alegavam as dificuldades enfrentadas no final da década anterior, em decorrência da depreciação cambial e da queda do fluxo de importação. Contudo, o início da década de 1920 apresentava novas e boas perspectivas: de um lado, as dificuldades internacionais haviam cessado, e de outro lado, inaugurava-se a Usina Hidroelétrica de Bananeira, que a partir de então aumentava a oferta de energia e reduzia os custos dos serviços oferecidos pelas empresas controladas pela Companhia Brasileira de Energia Elétrica. ${ }^{23}$

As reclamações constantes contra os maus serviços prestados pelas companhias cresceram durante o período da Primeira Guerra Mundial. Os jornais diariamente reclamavam da falta de bondes, do desrespeito aos horários e das irregularidades nas obras. Segundo relatava o Diário de Notícias de 9 de abril de 1915: "As empresas de bondes, que tão mal servem o povo, não conhecem, absolutamente, poder algum que as possa compelir a execução regular de suas obrigações". As reclamações eram ainda maiores, especialmente 
diante dos serviços prestados pela Intendência na cidade baixa. Tais serviços se encontravam praticamente em total abandono, já que a municipalidade não tinha recursos disponíveis para liquidar as dívidas assumidas com a encampação da Bahia Light, e muito menos para ampliar e reformar as linhas de bondes e redes de iluminação. Assim, em 1921 a prefeitura passava para a Companhia Linha Circular os serviços de iluminação das áreas anteriormente atendidas pela d'Eclairage. Contudo, o serviço de transporte também seria transferido, mas quase uma década depois, em 1929. Após concorrência pública, o município passou todos os bens adquiridos da Bahia Light, com material fixo e rolante, outras instalações e a concessão de transporte da cidade baixa, para a Companhia Linha Circular. ${ }^{24}$

A venda foi consolidada em meados de maio de 1929, tendo se acertado, pela lei $n^{\circ}$ 803, o preço dos bens da Bahia Light em 8.112:000\$000 réis. Evidentemente, parte desse valor seria utilizado pelo município para quitar a antiga dívida com Percival Farquhar, de maneira que 5.112:000\$000 (ou cerca de 125 mil libras) foram depositados no Bank of London South America "para quitação da dívida municipal e exoneração da hipoteca dos bens encampados a Bahia Light and Power e Cia. d'Eclairage de Bahia de 1914". ${ }^{25}$ Três anos antes da compra dos bens da Bahia Light, em 1926, houve a fusão definitiva entre as Companhias Linha Circular e Trilhos Centrais. As empresas, que já funcionavam com os mesmos diretores desde o controle acionário da Guinle \& Co., em 22 de setembro de 1926 tiveram a unificação de seus bens na Companhia Linha Circular, que aumentava o capital da empresa para mais de oito mil contos de réis. ${ }^{26}$

Assim a Companhia Linha Circular chegava ao final da década de 1920 assumindo o monopólio dos serviços de distribuição de energia elétrica e transporte urbano da cidade de Salvador. A capital baiana havia crescido e se modernizado: em 1926 eram 321.702 habitantes, e a empresa em 1927 comemorava o número de 60 milhões de passageiros transportados durante seus vinte anos de serviços prestados à capital, enquanto o consumo de energia domiciliar e comercial ultrapassava os 3 milhões de $\mathrm{kW}$. Contudo, ainda os dois últimos anos da década de 1920 guardavam mudanças profundas no comando do fornecimento dos serviços para Salvador. Seguindo a tendência de parte considerável das concessões da Companhia Brasileira de Energia Elétrica, estas em 1927 passaram para o controle acionário da empresa norte-americana Amforp. A Amforp (American Foreign Power, atuando também como Bond \& Share) era empresa constituída pela norte-americana, fabricante de materiais elétricos, General Electric. Desde o início do século XX a relação 
próxima entre CBEE e General Electric possibilitou que os empresários norte-americanos tivessem acesso facilitado ao mercado brasileiro.

Em 30 de abril de 1929, assembléia da empresa autorizava a mudança da razão social da Companhia Brasileira de Energia Elétrica para Cia. Energia Elétrica da Bahia, aprovada pelo Decreto nº 6.221 do governo do estado da Bahia. Contudo, nesse momento os serviços de distribuição de iluminação e energia elétrica eram separados definitivamente dos serviços de transporte urbano. Enquanto a Companhia Energia Elétrica da Bahia ficava com as concessões de energia elétrica, a Companhia Linha Circular, por contrato de 28 de maio de 1929, obteve o direito de explorar o serviço de viação em todo o município de Salvador, que manteve até 1955.

Desta forma, a característica de Salvador como capital dos contrastes permanecia: a extrema concentração tanto do poder político como do poder econômico da elite local possibilitou a modernização da cidade, com introdução de tecnologia e serviço de ponta, enquanto parcela considerável da população continuava vivendo em condições precárias. Os antigos arrabaldes que agora estavam "mais próximos" do centro, como Vitória e Farol, mantinham o padrão de vida de cidades européias, enquanto bairros mais populares e distantes sofriam com a falta de recursos básicos. No que diz respeito às empresas de transporte, o setor sofreu um grande processo de concentração e monopolização, seguindo a tendência das principais cidades brasileiras. A Guinle \& Co., que havia lutado intensamente contra a Light nos mercados de São Paulo e do Rio de Janeiro, e perdido, utilizou-se do principal recurso da empresa estrangeira para sustentar o mercado soteropolitano: a aliança com o poder local.

\section{NOTAS}

${ }^{1}$ Este artigo é uma versão ligeiramente modificada do texto "História do transporte urbano e público na cidade de Salvador na Primeira República" apresentado no VII Congresso Brasileiro de História Econômica e $8^{\text {a }}$ Conferência Internacional de História de Empresas, organizados pela Associação Brasileira de Pesquisadores em História Econômica (ABPHE), realizado em Aracaju entre 2 e 5 de setembro de 2007.

${ }^{2}$ As informações sobre sistema de transporte urbano de Salvador no período anterior à Primeira República foram extraídos de: SAMPAIO, Consuelo. 50 anos de urbanização: Salvador da Bahia no século XIX. Rio de Janeiro: Versal, 2005. p.183. Referências sobre a introdução dos serviços de transportes urbanos e iluminação são tratadas de maneira superficial em MORRISON, Allen. The tramways of Brazil: a 130-years survey. New York: 
Bonde Press, 1985, e de maneira tangencial nos trabalhos de: BARROS, Geraldo M. Guilherme Guinle: 1882-1960. Rio de Janeiro: Agir, 1982, e de GAULD, Charles A. Farquhar, o último titã. São Paulo: Ed. de Cultura, 2006. Um excelente levantamento de fontes das empresas de transporte e energia elétrica no Estado foi realizado por MEMÓRIA DA ELETRICIDADE. Acervo histórico da Companhia de Eletricidade do Estado da Bahia. Rio de Janeiro: Centro de Memória da Eletricidade e Coelba, 1995. Sobre a economia e sociedade baiana da Primeira República ver: SAMPAIO, José Luís Pamponet. A inserção da Bahia na evolução nacional: 1ํㅡㄹ Etapa: 1850-1889. Salvador: Governo do Estado da Bahia, 1978; e as poucas teses e dissertações da Universidade Federal da Bahia são: BELÉNS, Adroaldo de Jesus (2002). A modernidade sem rosto. Salvador e a telefonia (1881-1924); FONSECA, Raimundo (2000). Fazendo Fita: cinematographos, cotidiano e imaginário em Salvador (18971930); CASTELLUCCI, Aldrin (2001). Salvador dos operários. Uma história da greve de 1919 na Bahia; e LEITE, Rinaldo (1996). E a Bahia civiliza-se... Idéias de civilização e cenas de anticividade em um contexto de modernização urbana: Salvador 1912-1916. Finalmente, os principais trabalhos de história política da Bahia são: PANG, Eul-Soo. Bahia in the First Brazilian Republic. Coronelismo and Oligarchies, 1889-1934. Gainesville: University Presses of Florida, 1979; e SAMPAIO, Consuelo. Os partidos políticos da Bahia na Primeira República: uma política de acomodação. Salvador: Ed. UFBA, 1978.

${ }^{3}$ A Bahia Light foi uma empresa formada pelo empresário norte-americano Percival Farquhar. Muito embora tenha recebido apoio inicial dos empresários Alexander Mackenzie e Fred Pearson, diretores da São Paulo Light e Rio Light, a empresa baiana não manteve a mesma administração daquelas do Rio de Janeiro e de São Paulo. Financeiramente, enquanto as empresas de São Paulo e do Rio de Janeiro estavam mais diretamente ligadas ao capital canadense, a Bahia Light foi um empreendimento sustentado pelos investimentos de Farquhar e suas conexões com os centros financeiros de Nova York e Paris. As administrações se diferenciavam também porque Mackenzie e Pearson eram personagens presentes e bem relacionados com a elite local de suas concessões, enquanto ao que parece o negócio de Farquhar era secundário dentro de seu complexo de negócios no Brasil, que incluía o Porto do Pará, a ferrovia Madeira-Mamoré, e tantas outras ferrovias em São Paulo e no sul do Brasil. Para a história da Bahia Light: GUALD (2006); e para a história da Light no Brasil: ARMSTRONG, C. \& NELLES, H. Southern exposure: Canadian promoters in Latin America and the Caribbean: 1896-1930. Toronto: University of Toronto Press, 1988; McDOWALL, Duncan. The Light. Brazilian Traction, Light and Power Company Limited: 18991945. Toronto: University of Toronto Press, 1988; e SOUZA, Edgar. A história da Light. Os primeiros 50 anos. São Paulo: Eletropaulo, 1982. Para a história da Companhia Brasileira de Energia Elétrica, a concorrente da Light nos mercados de São Paulo, Rio de Janeiro e Salvador. ver: BARROS, 1982, HANSEN, Cláudia. O poder da Companhia Brasileira de Energia Elétrica em Petrópolis (1909-1927). Dissertação (Mestrado) - UFF, Niterói, 2006; e HONORATO, Cezar. O polvo e o porto. A cia. Docas de Santos (1888-1914). São Paulo: Hucitec, 1996.

${ }^{4}$ Para uma síntese sobre os conflitos em São Paulo e no Rio de Janeiro ver: HANSEN, Cláudia; SAES, Alexandre. "Poder Municipal e as concessões de serviços públicos no Brasil no 
início do século XX”. História Econômica \& História de Empresas. ABPHE. v.I, 2007. Para os conflitos na formação do setor de eletricidade do Rio de Janeiro: HANSEN, 2006, LAMARÂO, Sério. A energia elétrica e o parque industrial carioca (1880-1920). Tese (Doutorado) - UFF, Niterói, 1997; WEID, Elisabeth Von der. "Estratégias de implantação de uma multinacional numa cidade latino-americana: The Rio de Janeiro Tramway, Light and Power Co. Ltd. 1899-1920". Anais do II Congresso Brasileiro de História Econômica. v.IV. Niterói, 1996. Para os conflitos na formação do setor de eletricidade em São Paulo: MARANHÃO, Ricardo. "Estado e capital privado na eletrificação de São Paulo" in: SZMRECSÁNYI, Támas; MARANHÃO, Ricardo. História de empresas e desenvolvimento econômico. São Paulo: Hucitec, 2002; SAES, Flávio. A grande empresa de serviços públicos na economia cafeeira. São Paulo: Hucitec, 1986, LORENZO, Helena. Eletrificação, urbanização e crescimento industrial no estado de São Paulo. Tese (Doutorado) - Unesp, Rio Claro, 1993; SEGATTO, José Antônio. "Relações e conflitos de trabalho na Light de São Paulo”. In: SZMRECSÁNYI, Támas; MARANHÃO, Ricardo. História de empresas e desenvolvimento econômico. São Paulo: Hucitec, 2002; SILVA, Heloísa Barbosa. "Batalhas pelo monopólio”. In: ELETROPAULO. História e Energia. A chegada da Light. São Paulo: Eletropaulo, 1986; PONTES, José Alfredo. “A Light e a Imprensa”. Memória, São Paulo: Eletropaulo, n.22, 1995.

${ }^{5}$ SAMPAIO, 2005. Para a autora essa foi uma condição peculiar da economia baiana, em que empresários locais tornavam-se os principais agentes da modernização dos serviços públicos. Contudo, devemos lembrar que no estado de São Paulo essa foi uma tendência repetitiva em diversas cidades: "o grande capital cafeeiro" era o responsável pela construção das ferrovias, fundação de bancos e criação de empresas de serviços públicos em cidades como São Paulo, Santos, Campinas e Ribeirão Preto, entre tantas outras. Entre alguns exemplos podemos citar as empresas de transporte de São Paulo, como: a Companhia Carris de Ferro de São Paulo, a Companhia Ferro-Carril de São Paulo, a Companhia São Vicente e a Empresa Vila Mathias. Entre seus empresários e acionistas estavam Francisco de Paula Mayrink e Antônio da Silva Prado, eminentes fazendeiros de café e empresários locais. SILVA, 1986, p.47.

${ }^{6}$ Arquivo Coelba, T.5.4.009, 13 dez. 1899.

${ }^{7}$ Em fins de 1898 os direitos da Companhia Transportes Urbanos eram legalmente passados para a Linha Circular, e esta empresa logo se adiantou em estender seus direitos para as novas concessões: "A Companhia Linha Circular de Carris da Bahia precisa que V.E. lhe mande dar por certidão o teor da lei n.330 de 4 de julho de 1898 que concedeu à suplicante prorrogação por 30 anos de favores concedidos em virtude da lei provincial n. 2.406 de 20 de julho de 1883, com extensão dos mesmos às linhas da antiga Companhia Transportes Urbanos e bem assim do teor do contrato de 13 de outubro de 1899, lavrado nesta Intendência para execução daquela lei”. Bahia, 2 nov. 1898. Arquivo Coelba. T.5.4.035.

${ }^{8}$ Arquivo Coelba, T.5.4.035, 14 fev. 1905.

${ }_{9}^{9}$ Arquivo Coelba, T.22.4.001, 24 out. 1907.

${ }^{10}$ Arquivo Coelba, T.23.4.005, 5 nov. 1907. 
${ }^{11}$ GAULD, 2006, p.125. O valor do capital da Bahia Light em réis (taxa de câmbio média de 1907 a 3,1) era de 10.850:000\$000 réis; praticamente o valor da receita do estado da Bahia em 1907, de 12.744:739\$210.

${ }^{12}$ Arquivo Municipal de Salvador. Atas da Câmara, 27 fev. 1907.

${ }^{13}$ Alfredo Valadão foi quem elaborou o primeiro projeto federal sobre a produção e fornecimento de energia elétrica, já em 1904. Contudo seu projeto levaria cerca de trinta anos para ser aprovado, como o Código de Águas, com a centralização do governo de Getúlio Vargas.

${ }^{14}$ Arquivo Municipal, Intendência Processos, 21 mar. 1909.

${ }^{15}$ Diário de Notícias, 9 out. 1909.

${ }^{16}$ Arquivo Municipal, Intendência Processos, 5 out. 1909.

${ }^{17}$ No discurso do vereador sr. Prediliano Pitta fica claro esse apoio ao empresário Guilherme Guinle: "Já é público o pensamento de se render uma homenagem aos atuais dignos diretores da Companhia Linha Circular, que, indiscutivelmente, bastante tem contribuído com esforços manifestos para o progresso material desta cidade”. Arquivo Municipal. Atas do Conselho Municipal, 27 set. 1909.

${ }^{18}$ Arquivo Público do Estado da Bahia. Relatório de Presidente de Estado. José Marcelino de Souza, 1906.

${ }^{19}$ Arquivo Municipal. Atas do Conselho Municipal, 2 set. 1911.

${ }^{20}$ Arquivo Municipal. Atas do Conselho Municipal, 17 jun. 1912.

${ }^{21}$ Os debates sobre a encampação da d'Eclairage foi iniciado no Conselho Municipal, em 27 mar. 1907. Contudo a Bahia Light foi absorvida nesse processo apenas depois de 1911. Arquivo Municipal de Salvador. Atas do Conselho Municipal, 27 mar. 1907.

${ }^{22}$ Em 1915, a dívida do Município com a Light representava cerca de um terço de toda a dívida municipal. Arquivo Municipal de Salvador. Atas do Conselho Municipal, 21 jan. 1915.

${ }^{23}$ Arquivo Municipal. Intendência Processos, 11 maio 1921.

${ }^{24}$ MEMÓRIA DA ELETRICIDADE, v.II, 1995. p.22.

${ }^{25}$ Arquivo Coelba, T.5.2.224., 28 maio 1929.

${ }^{26}$ Arquivo Coelba, T.16.5.032., 22 set. 1926.

Artigo recebido em outubro de 2007. Aprovado em dezembro de 2007. 